Ann. Geophysicae 16, 698-710 (1998) @ EGS - Springer-Verlag 1998

\title{
Equatorial electrojet as part of the global circuit: a case-study from the IEEY
}

\author{
A. T. Kobea ${ }^{1}$, C. Amory-Mazaudier ${ }^{2}$, J. M. Do ${ }^{2}$, H. Lühr ${ }^{3}$, E. Houngninou ${ }^{1}$, J. Vassal ${ }^{2}$, E. Blanc ${ }^{4}$, J. J. Curto ${ }^{5}$ \\ ${ }^{1}$ U. F. R. SSMT / Laboratoire de Physique de l'Atmosphère, 22 B.P. 582 Abidjan 22, Côte d'Ivoire \\ Tel: 2254449 82; Fax: 2254449 82/44 38 47; e-mail: kobeat@syfed.ci.refer.org \\ ${ }^{2}$ Centre d'Etudes des Environnements Terrestres et Planétaires(CETP), Observatoire de Saint-Maur. 4, avenue de Neptune, \\ F-94107 Saint-Maur-Des-Fossés, France \\ ${ }^{3}$ Institut für Geophysik und Meteorologie der Technischen Universität Braunschweig, Mendelssohnstrass 3, D-38106 Braunschweig, \\ Germany \\ ${ }^{4}$ Commissariat à l'Energie Atomique, Laboratoire de Détection et de Géophysique, BP 12, F-91680 Bruyères-le-Châtel, France \\ ${ }^{5}$ Observatorio de Ebre, E-43520 Roquetes, Tarragona, Spain
}

Received: 13 December 1996 / Revised: 18 September 1997 / Accepted: 9 January 1998

\begin{abstract}
Geomagnetic storm-time variations often occur coherently at high latitude and the day-side dip equator where they affect the normal eastward Sq field. This paper presents an analysis of ground magnetic field and ionospheric electrodynamic data related to the geomagnetic storm which occured on 27 May 1993 during the International Equatorial Electrojet Year (IEEY) experiment. This storm-signature analysis on the auroral, mid-latitude and equatorial ground field and ionospheric electrodynamic data leads to the identification of a sensitive response of the equatorial electrojet (EEJ) to large-scale auroral return current: this response consists in a change of the eastward electric field during the pre-sunrise hours (0400-0600 UT) coherently to the high-, mid-, and equatorial-latitude $H$ decrease and the disappearance of the EEJ irregularities between the timeinterval 0800-0950 UT. Subsequent to the change in h'F during pre-sunrise hours, the observed foF2 increase revealed an enhancement of the equatorial ionization anomaly (EIA) caused by the high-latitude penetrating electric field. The strengthening of these irregularities attested by the Doppler frequency increase tracks the $H$ component at the equator which undergoes a rapid increase around $0800 \mathrm{UT}$. The $\Delta H$ variations observed at the equator are the sum of the following components: $S_{R}$, $D P, D R, D C F$ and $D T$.
\end{abstract}

Keywords. Equatorial electrojet - Magnetosphereionosphere interactions - Electric fields and currents . Auroral ionosphere $\cdot$ Ionospheric disturbances

\section{Introduction}

Variations in ground magnetic field are produced by different current systems flowing in the ionosphere and

Correspondence to: Dr. A. T. Kobea magnetosphere. The regular variation of the ground magnetic field $S_{R}$ has been studied by Mayaud (1965), and characterizes field component variations produced by regular ionospheric electric currents. As regards the world geomagnetic disturbance $D$ observed on the ground magnetic field record, it can be expressed as follows from the physical viewpoint:

$D=D R+D P+D C F+D T$,

where each term has the following meaning (Akasofu and Chapman, 1961): $D R$ : magnetic disturbance field produced by the ring current flowing in the equatorial plane of the magnetosphere; $D P$ : magnetic disturbance caused primarily by intense electrojets flowing in the ionosphere of polar regions (including the auroral zone) and their accompanying currents in the ionosphere or magnetosphere or both; $D C F$ : magnetic field produced by the electric current at magnetopause owing to the interaction of the earth's permanent field with the solar wind; DT: magnetic field produced by the electric current flowing in the tail region of the magnetosphere from the dawn to the dusk side.

The ground magnetic field variations recorded at different latitudes allow both to identify the relative importance of the various components described and integrate their magnetic effects at different times during the geomagnetic storm of 27 May 1993. Such globalscale disturbances have been the subject of interest in many studies, for example Mazaudier et al. (1987) and Fambitakoye et al. (1990). Much research has been carried out on the equatorial electrojet (EEJ). However, there are many aspects not yet well understood which are still worth studying. One of these aspects is the response of the EEJ to the disturbances originating from solar wind-magnetosphere-ionosphere interactions (Reddy, 1981, 1989). It is well known that many types of global-scale disturbance exhibit an enhancement at the EEJ latitudes (Onwumechilli and Ogbuehi, 1962; Akasofu and Chapman, 1963; Onwumechilli et al., 1973). Much data analysis has been performed which delineates the relationship between auroral magnetic 
field and the equatorial variations in the magnetic field, in foF 2 , in the occurrence of irregularities or the electric field serving as the primary driver for the equatorial ionization anomaly or EEJ (Abdu et al., 1988; Fejer, 1986; Rastogi, 1973b; Reddy et al., 1979; Tanaka 1986; Tanaka and Ohtaka, 1996).

This paper contributes further to this area of study. It presents the EEJ response to large-scale auroral zone return currents during the geomagnetic storm of 27 May 1993 and shows the effects of the electric field penetration on the electrodynamic development of the equatorial ionosphere. To interpret the evolution of this disturbance on the global scale, we took into account magnetic field data from auroral, middle and equatorial latitude. Table 1 presents the list of the magnetic observatories of this study.
In Sect. 2, we present the geophysical context prevailing during the selected period and the analysis of the observed magnetic field variations at equatorial latitude. The auroral and mid-latitude data are described in Sect. 3. The related electrodynamic data analysis at middle and equatorial latitude are presented in Sect. 4. The synthesis of the different observations follows in Sect. 5.

\section{Geophysical context and equatorial magnetic data analysis}

Table 2 presents the geophysical context of the selected period from 25 to 28 May 1993. It should be remembered that the equatorial $D s t$ gives an estimate of the

Table 1. The position of the ground magnetometers, ionosondes (*) and HF radar (')

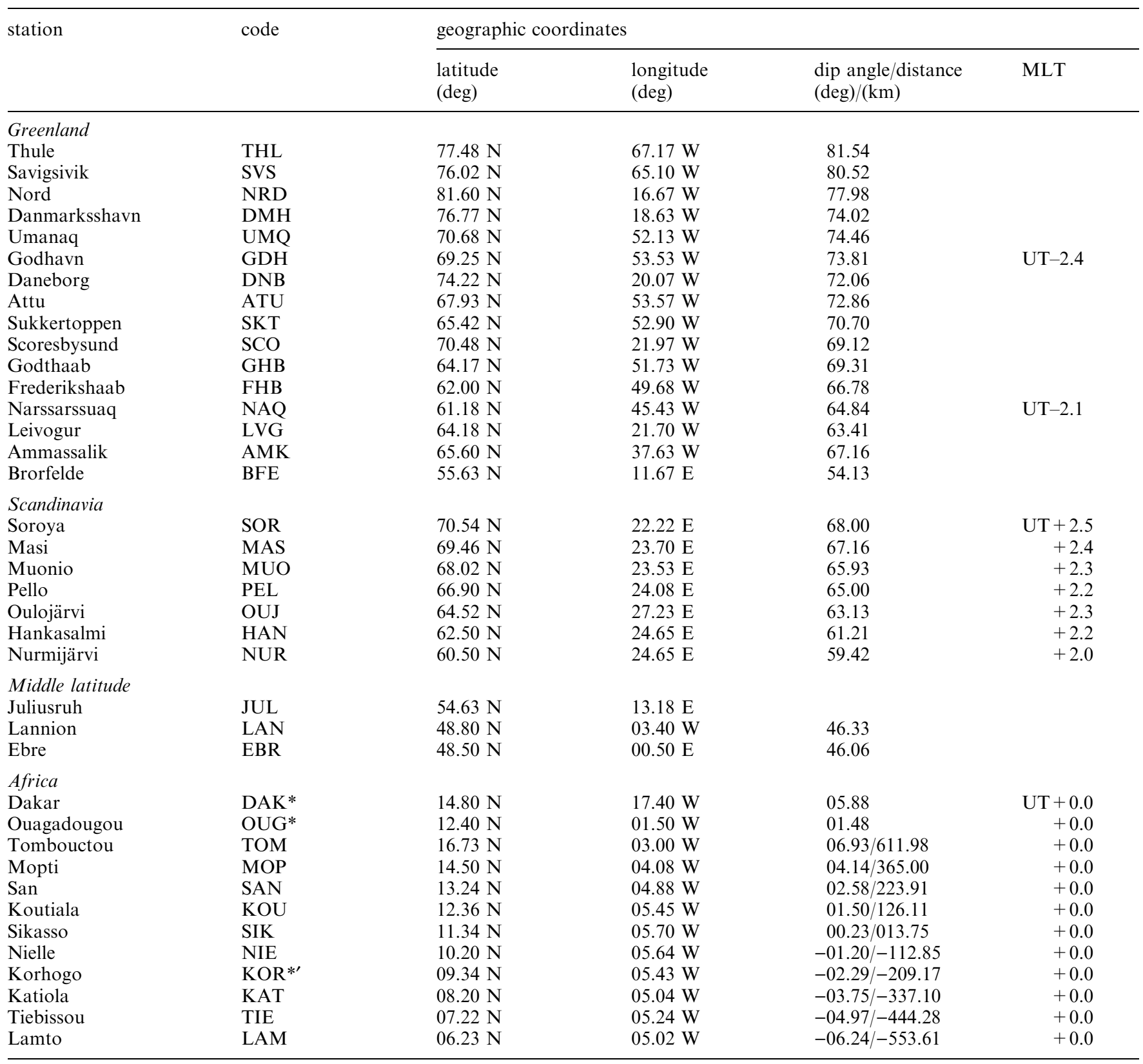


Table 2. Geophysical context of the case-study

\begin{tabular}{|c|c|c|c|c|c|c|}
\hline \multirow[t]{2}{*}{ day } & \multicolumn{2}{|c|}{$\begin{array}{l}\text { equatorial } D s t \\
\text { extrema }\end{array}$} & \multirow[t]{2}{*}{$\operatorname{Ap}(\gamma)$} & \multirow[t]{2}{*}{$\Sigma \mathrm{km}(\gamma)$} & \multirow[t]{2}{*}{$\begin{array}{l}\text { auroral } \\
\text { electrojet }\end{array}$} & \multirow[t]{2}{*}{$\begin{array}{l}\text { mid-latitude } \\
\text { observations }\end{array}$} \\
\hline & $\min$ & $\max$ & & & & \\
\hline 26 Мay 1993 & 0 & +28 & 4 & 7 & nought & $H$ focus $/ D$ normal \\
\hline 27 May 1993 & -35 & +50 & 18 & 26 & $\begin{array}{l}\text { Westward then } \\
\text { Eastward equivalent } \\
\text { current }\end{array}$ & $\begin{array}{l}\text { Eastward then } \\
\text { Westward current } \\
\text { at } 0800 \text { UT } \mathbf{J n o r t h}+\mathbf{J} / /\end{array}$ \\
\hline 28 May 1993 & \multicolumn{2}{|c|}{ recovery phase } & 23 & 29 & & \\
\hline
\end{tabular}

sum of the $D R$, the $D C F$ and the $D T$ current, and depicts the different phases of a magnetic disturbance (Akasofu, 1964, 1972). Km and Ap indices describe global magnetic activity. The selected period is characterized by a sudden commencement of the disturbance on 26 May 1993 at 2230 UT subsequent to five consecutive fairly quiet days (Ap $<4$ for each of these days). 25 May 1993 appears as a magnetically fairly quiet day $(\mathrm{Ap}=2)$ preceeding the day of the storm.
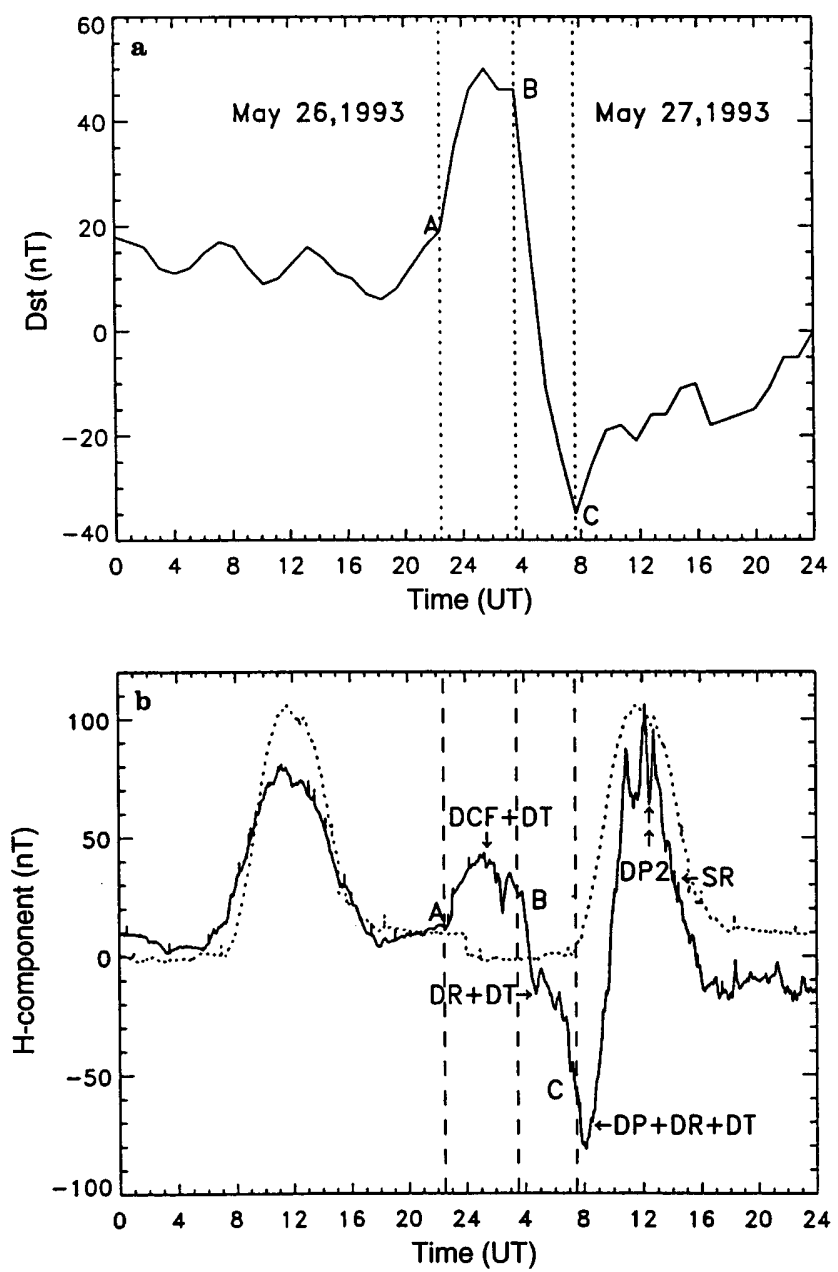

Fig. 1. a Equatorial Dst time variations on 26 and 27 May 1993. The letters A, B, and C indicate, respectively, the time of the storm onset (the SSC), the beginning of the main phase and the recovery phase. b-d Synopsis diagram of $\mathrm{H}$-, $D$ - and $Z$-component amplitude
Hence, we use it as the reference day according to the criteria given by Mayaud (1965) to analyse the day-today variability of the regular variation of the earth's magnetic field.

Figure 1a shows the equatorial Dst time variations on 26 and 27 May 1993. A magnetic disturbance started on 26 May 1993 at 2230 UT as indicated with the letter A. The initial phase reached $+50 \mathrm{nT}$ as peak amplitude at $\sim 0130$ UT, and lasted until 0330 UT on 27 May.
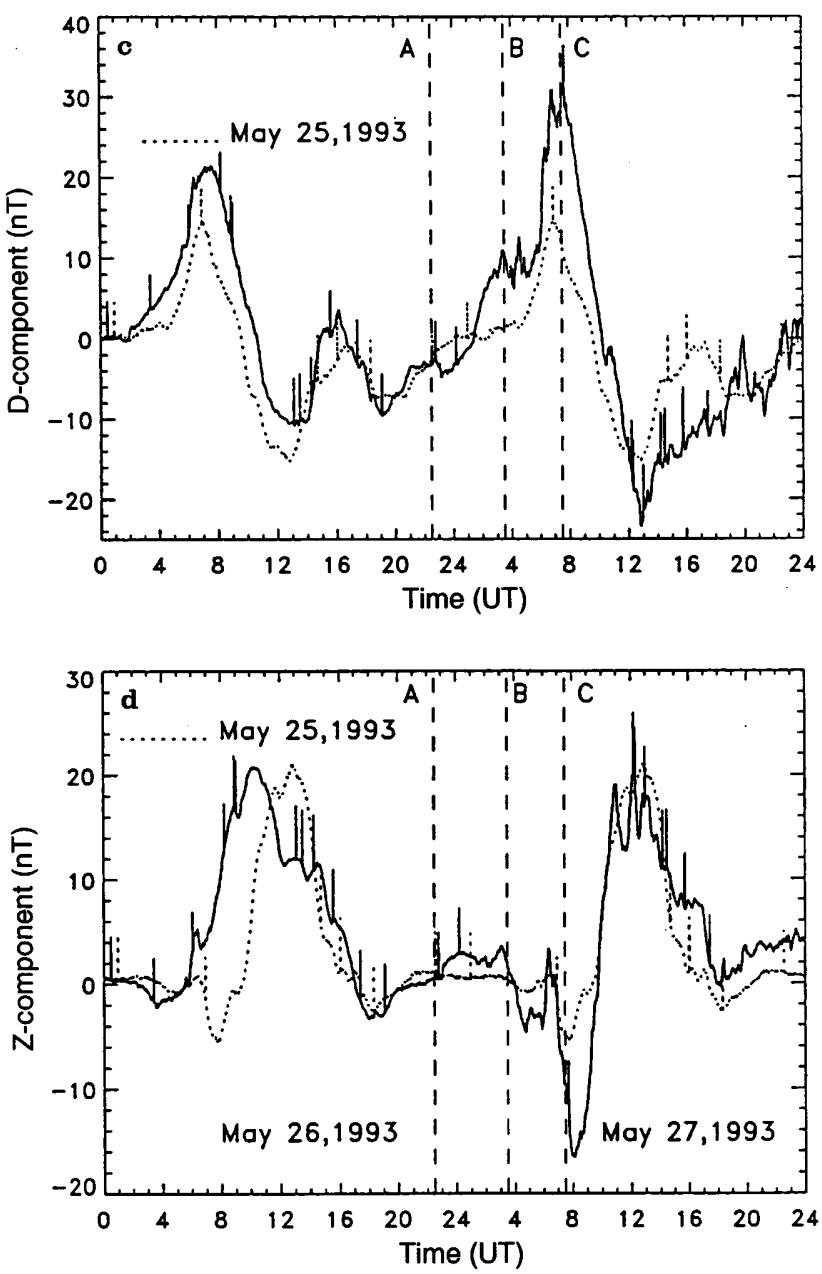

variations for 26 May (on the left) and 27 May 1993 (on the right) in solid line, overlaid by those of the reference quiet day (25 May $1993)$ in dotted line, at NIE $\left(10.20^{\circ} \mathrm{N} ; 05.63^{\circ} \mathrm{W}\right.$, dip: $\left.-01.20^{\circ}\right)$ near the EEJ maximum. NB: LT $=\mathrm{UT}$ 
This continuing compression of the geomagnetic field persisted for $5 \mathrm{~h}$. This period is followed by the main phase of the storm characterized by the decrease in Dst that peaked at a value of $-35 \mathrm{nT}$ at $0730 \mathrm{UT}$. It should be noted that the specific characteristic of this disturbance consists in the time duration and the amplitude of the initial phase which are nearly of the same magnitude as those of the main phase, contrary to most storms. Such morphological characteristics differ from the three typical average signatures of the equatorial Dst (Sugiura and Chapman 1960).

Fig. $1 \mathrm{~b}-\mathrm{d}$ shows the plot of $H, Z$ and $D$ variations at NIE overlaid in a dotted line by those of the reference quiet day, that is 25 May 1993. We may observe that the $H$-component variations track the $D s t$ between 2230 and $0330 \mathrm{UT}$; as the ionosphere does not form at that time, these stations are under the direct influence of the Chapman-Ferraro (DCF) and the DT current, which effect can only clearly be detected on the equatorial magnetograms due to the equatorial plane location of its source. These current effects are less pronounced on the middle latitude as observed at Ebro (Fig. 7). During the main phase of the storm, the $H$-component still continues to track the Dst variations between 0330 and $0730 \mathrm{UT}$; this means, the equator undergoes the ring current and the tail current effects. However, an appreciable increase in the $H$-component can be clearly detected between 0500 and 0730 UT indicating an eastward jet circulation during that period. The $\mathrm{H}$ component continues to decrease after the end of the Dst main phase at $0730 \mathrm{UT}$, as noticeable in Fig. $1 \mathrm{~b}$. Afterwards, the $H$-component increases to reach a value of $95 \mathrm{nT}$ at $1200 \mathrm{UT}$ and appears partly as typical variations of $S_{R}$. However, it appears depressed by about $25 \mathrm{nT}$ from the quiet-time level. It is important to note the appreciable anti-phase (to $H$ deflection) increase in the $D$-component at the equator in the time-interval of 0330-0730 UT. Compared to the quietday variations, the $D$-component on 27 May 1993 at NIE has increased by about $16 \mathrm{nT}$ (Fig. 1c). This increase can also be observed on all the stations of the African profile (Fig. 2). Marked fluctuations exhibiting three distinct peaks can be observed on the crest of the $H$-component at NIE (Fig. 1b) and on the latitude profile of $H$ as well (not shown) with roughly $17 \mathrm{nT}$ for the first and second peaks if we measure from the base value obtained by connecting the minima of the magnetic fluctuations.

Figure 2 shows the hourly means of the $D, H$ and $Z$ components of the magnetic field variations recorded on 25 and 27 May 1993 along the $5^{\circ} \mathrm{W}$ meridian profile magnetic network operated in West Africa during the IEEY experiment. The $Z$-component variations are antisymmetrical in latitude with respect to SIK. During the daytime, $H$ exhibits a latitudinal enhancement from TOM to NIE near the EEJ centre ( $H$ maximum) at $10.85^{\circ} \pm 0.35^{\circ} \mathrm{N}$ for 1993 , (Doumouya, 1995) where it appears strongly amplified.

\section{$2.1 \mathrm{H}, \mathrm{D}, \mathrm{Z}$-component contour analysis}

Figure 3 shows the latitudinal variations versus the time (UT) of the $H$ and $Z$-components of the magnetic field

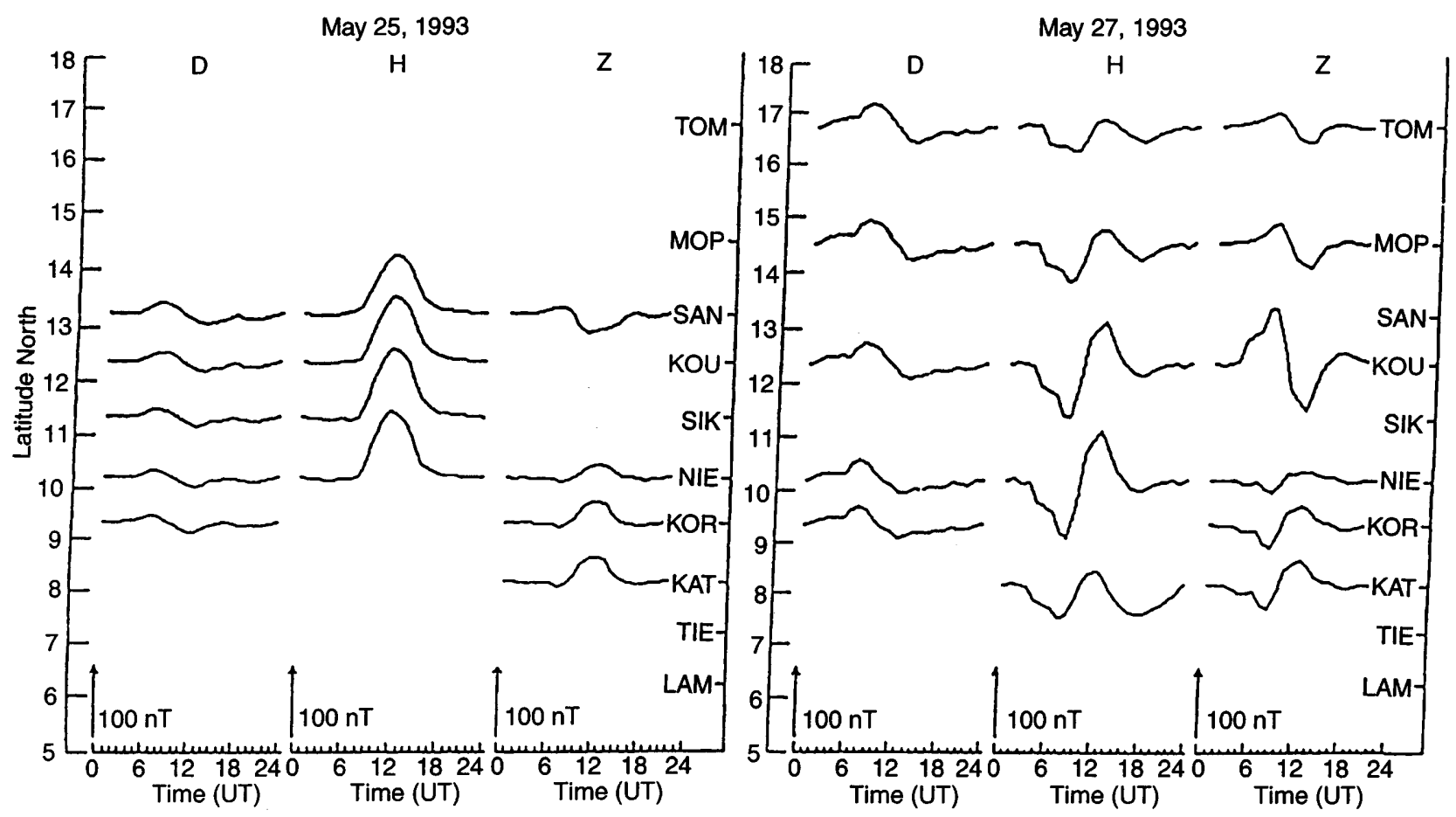

Fig. 2. Latitude profile of $D$-, $H$ - and $Z$-components (hourly means) recorded on the West African magnetic network on 25 May 1993 (the reference quiet day) on the left and 27 May 1993 on the right 

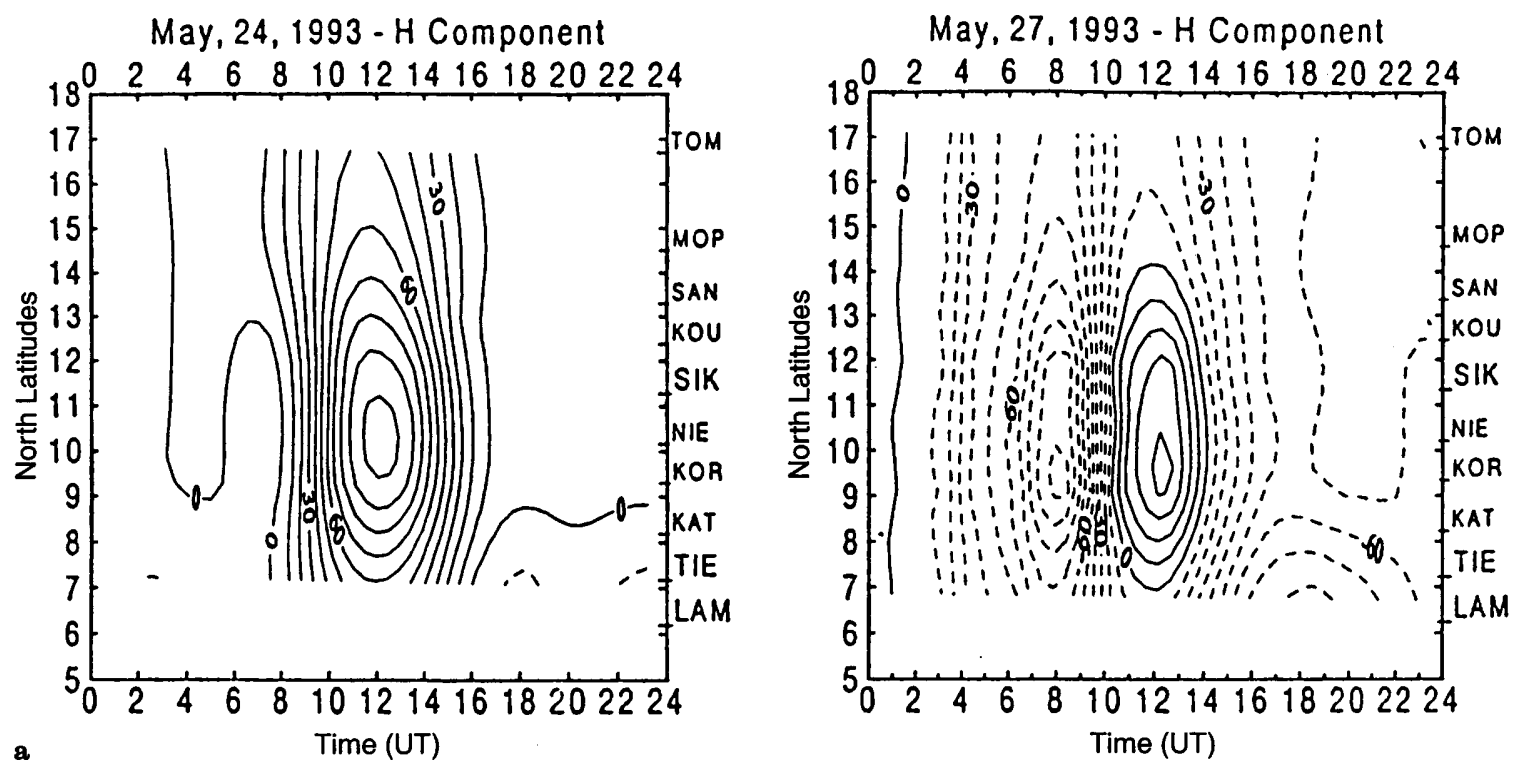

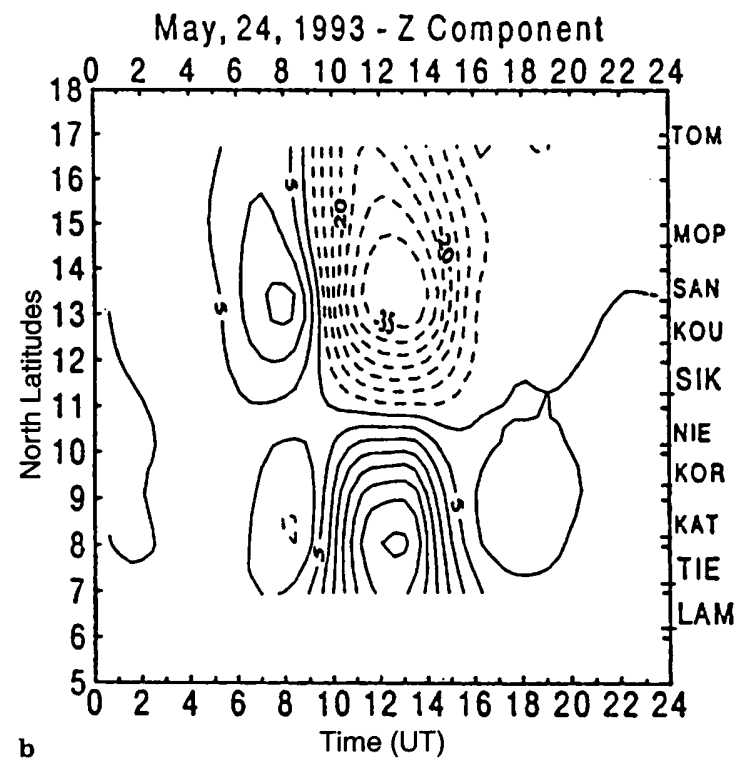

Fig. 3a,b. Isofield contours (drawn at 10-nT intervals) a for $\mathrm{H}$ component on 24, 27 May and b Z-component on 24, 27 May 1993 recorded on the West African network located approximately on the $5^{\circ} \mathrm{W}$ meridian profile. It is important to note that for quiet days the

for 24 May, a typical quiet-day pattern, and 27 May the disturbed day. It should be noted that for the quiet-day (data not available for the contour plot on 25 May), the contours of the $H$-component present a main cell centred on the local noon, near the latitude of the EEJ maximum at SIK (dip: $0.23^{\circ} \mathrm{N}$ ), featuring the quiet-day variations (Fig. 3a). Concerning the disturbed day, 27 May, the $H$ contours (Fig. 3a) present two cells: the first one observed in the morning is centred at $\sim 0800$ UT, the second cell, observed in the afternoon, is centred around 1200 UT near the latitude of the EEJ maximum at SIK.

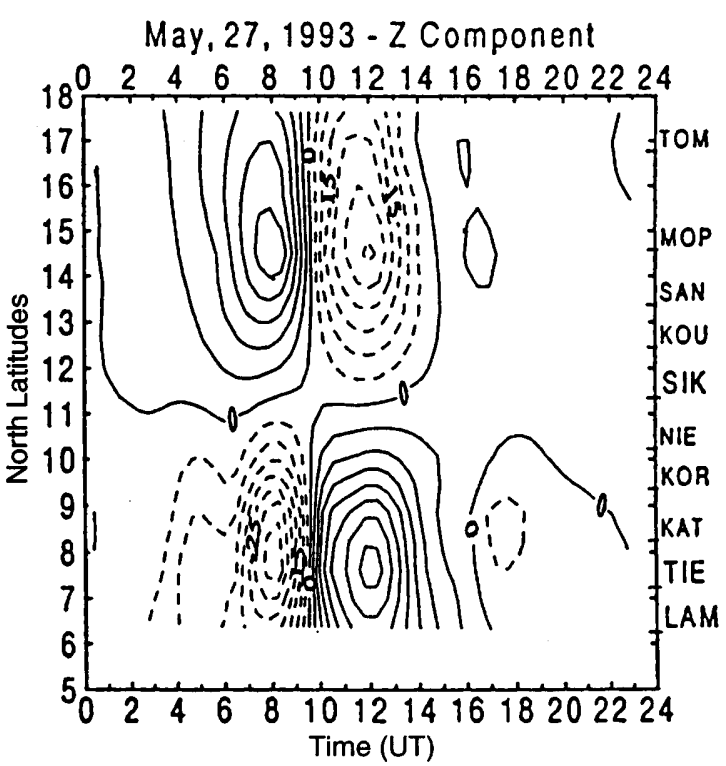

inversion of the jet circulation is indicated by the negative sign (dashed line) in the $H$-component, whereas the positive sign in the northern hemisphere (above SIK) of $Z$ plot attests to this jet inversion

Figure $3 \mathrm{~b}$ shows the patterns of $Z$ contours for 24 May, a quiet-day variation, and 27 May, the disturbed day. They depict the north-south anti-symmetry of the $S_{R}$. Both $H$ and $Z$ contours characterize the presence of the counter-electrojet (Doumouya, 1995). The counterelectrojet (CEJ) event is featured by the occurrence of the morning and afternoon cells on a quiet day. It should be remembered that the CEJ results from the appearance of a ribbon of current flowing inversely to the EEJ, and occurs either in the morning or in the afternoon or the whole day. It is noteworthy that Fig. 3a, b of 27 May appears as a CEJ event which is really none. 


\section{Auroral and mid-latitude data analysis}

We used data from auroral zone stations (Table 1) to identify the large-scale currents of 27 May 1993. On the plots of the $X$-component on the Scandinavian chain (Fig. 4) we can easily identify by the letter A the disturbance SSC on 26 May at 2230 UT. Around 0330 UT, at the beginning of the disturbance main phase (letter B), a westward electrojet is developing. It should be noted that in the present case the discontinuity is around noon (1200) even though it generally occurs around midnight (Harang discontinuity). Hence, the westward morning electrojet related to this discontinuity occurs in addition to the usual night-time reversal. All the stations record a westward equivalent current from 0330 to $0730 \mathrm{UT}$. The $X$-component amplitude peaked up a value of $350 \mathrm{nT}$ for the northernmost stations and $60 \mathrm{nT}$ for the sub-auroral ones. During this period, the amplitude remained nearly steady from Pello toward the sub-auroral stations. Just after 0900 UT, when the current reached the zero value on the northernmost stations to reverse later to flow eastwards, the subauroral stations continue to record a westward current. These observations suggest a development of a current cell simultaneously with the development of the ring current (main phase of the disturbance). During the period of increasing current, all the stations of the auroral network, namely those located under $72^{\circ} \mathrm{N}$ latitude, were south of the electrojet maximum. This is confirmed by the hourly latitude profiles (not shown) for the active period in the time-interval of $0330-1700 \mathrm{UT}$. Just after 0730 UT, when the recovery period started, and the Dst began to increase, the convection cell modified, hence the stations of the network were no longer south of the electrojet maximum. These observations suggest that the main activity on this day is located somewhat north of the Scandinavian chain. Striking observations on these Scandinavian recordings are the quasi-periodic fluctuations occurring in the timeinterval of 1100-1300 UT with a period of approximately $20-30 \mathrm{~min}$. It should be noted that these fluctuations are well in phase at all the stations of the Scandinavian chain and appear coherent with those observed in the same time-interval on the latitudinal profile of the $H$-component of the African chain. The three distinct peaks of these quasi-periodic fluctuations at the sub-auroral stations (OUJ, HAN, NUM) have roughly a magnitude of $105 \mathrm{nT}$ for the second peak at 1230 UT, when measured in the same manner as on the equatorial recordings.

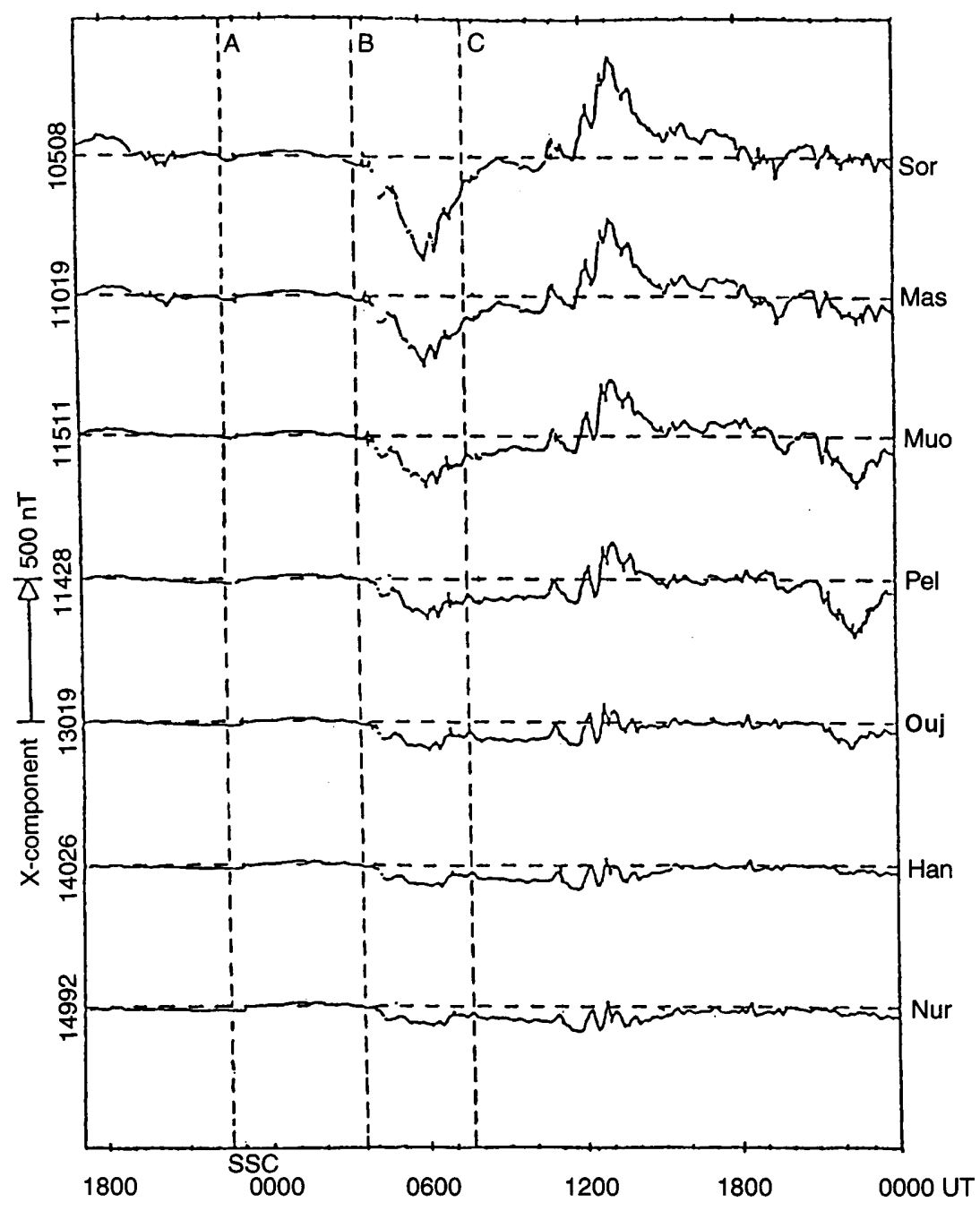

Fig. 4. $X$-component plot of magnetic field on 27 May 1993 observed on the Scandinavian magnetic network 
Parts a and b of Fig. 5 show respectively the $H$ component variations on 26 and 27 May 1993 recorded on the Greenland magnetic chain. On 27 May 1993, the Greenland magnetometers located within the same latitude range as those of the Scandinavian network, that is, $60^{\circ} \mathrm{N}-72^{\circ} \mathrm{N}$, exhibit a westward equivalent current in the time-interval 0400-0800 UT with a peak value of -600 and $-450 \mathrm{nT}$, respectively, for the southernmost stations NAQ and AMK; then an eastward jet begins from about 1000 UT with a peak value of 450 and $600 \mathrm{nT}$, respectively, at DNB and DMH. Recording at LVG exhibits a westward equivalent current on 27 May 1993 with a peak value of -440 nT between 0330-0730 UT in concert with the Greenland southernmost chain as can be seen on the $H$ and F-component plots (Fig. 6a, b). As a result of these observations, the remarkable continuously increasing amplitude from ATU, GDH, UMQ, respectively about 187.5, 300 and $375 \mathrm{nT}$ towards the easternmost stations under $80^{\circ} \mathrm{N}$ latitude (DNB, DMH respectively about 487 and $487.5 \mathrm{nT}$ ), suggest that the main activity is shifting north of the Scandinavian chain. This remark is quite consistent with the former one inferred from the
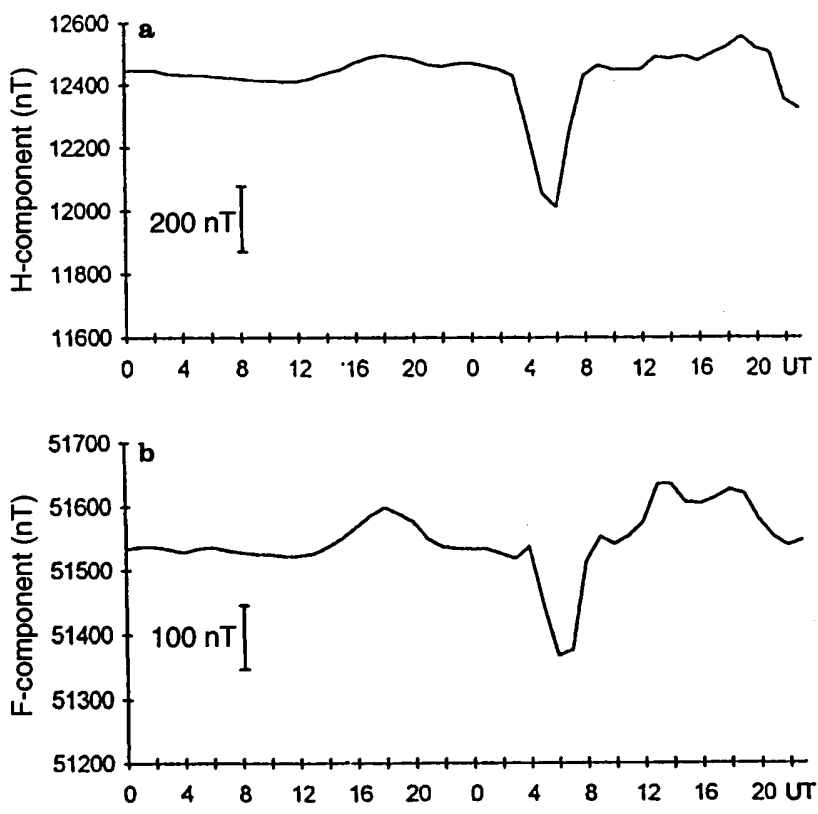

Fig. 6. a $H$-component variations on 26 and 27 May 1993 and $\mathbf{b}$ the magnetic field force for the same period recorded at LVG (dip: 63.41 ${ }^{\circ}$ )
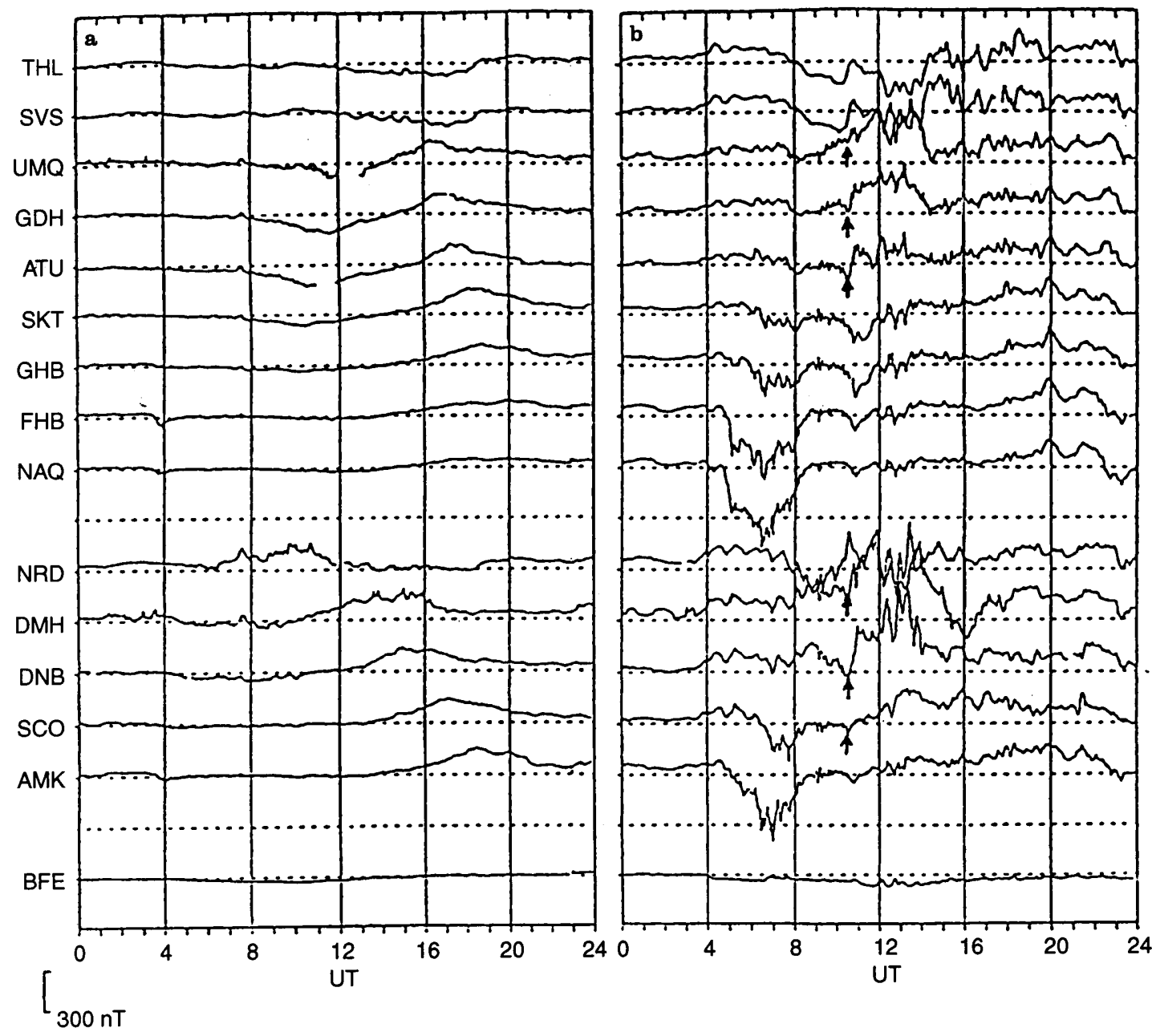

Fig. 5. a $H$-component on 26 May and b 27 May 1993 recorded on the Greenland chain. The arrows indicate the beginning of the eastward electrojet subsequent to the westward electrojet which occured at about $0400 \mathrm{UT}$ 


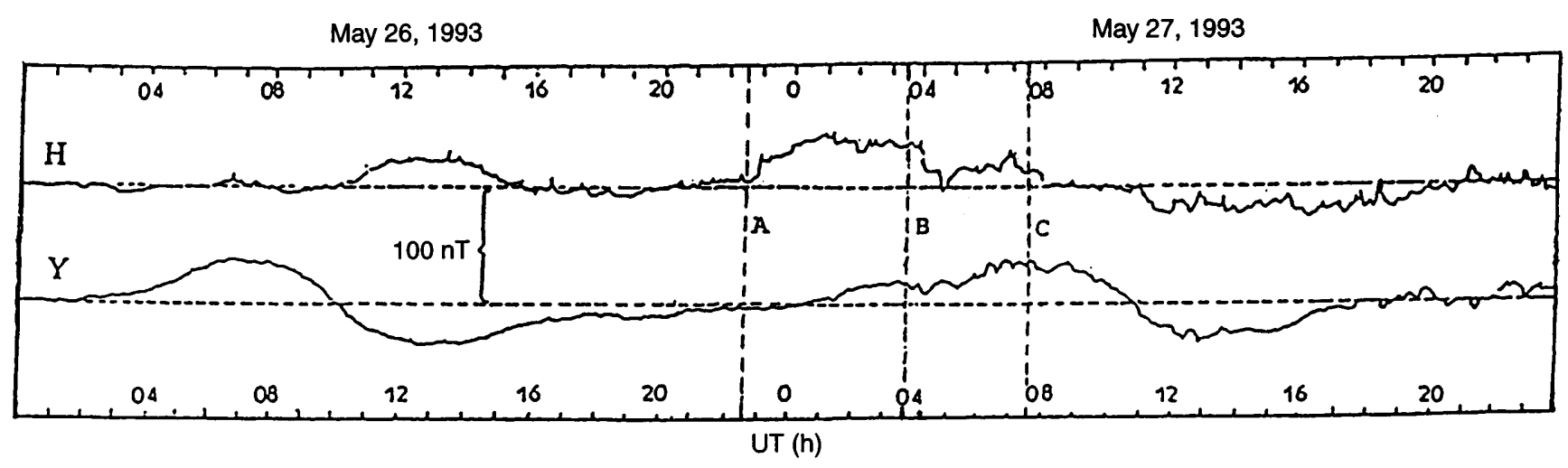

Fig. 7. $H$ - and $Y$-component of the earth magnetic field recorded at EBR (dip: 46.06 ${ }^{\circ}$ ) in mid-latitude on 26 and 27 May 1993

Scandinavian recordings. Otherwise, these recordings are properly in phase and characterize the same vortex observed both on the Scandinavian and the Greenland chain. Note also the appreciable fluctuations in phase at all latitudes namely at DNB, DMH, SKT, ATU, GDH and UMQ in the time-interval of 1100-1300 UT, as those observed on the African and Scandinavian recordings.

The mid-latitude $H$ and $Y$ or $D$ plots (Fig. 7) for the same event reveal that at the EBR station, the $\mathrm{H}$ component tracks the Dst variations in the time-interval of 2230-0330 UT with a peak value of $45 \mathrm{nT}$ at $\sim 0130$ UT. This is evidenced by the comparison with the quiettime variations on 25 May 1993 (not shown) during the same time-interval with a nearly null amplitude. Therefore, the EBR station undergoes the direct influence of the $D C F+D T$ current as the equatorial stations. During the subsequent period, that is, 0330-0730 UT, the $H$-component exhibits an amplitude of about $28 \mathrm{nT}$ up to the peak compared with the quiet-time level. These variations occur nearly in the same interval of time as those more appreciable in magnitude of the $D$-component at the equator. It is worthy of note that the $H$ and $Y$-component variations exhibit a very low magnitude compared to the same component variations at the equator because the EBR station is located near the line of the north focus of the Sq system. It should be noted that around $0730 \mathrm{UT}$, a negative $H$ deflection follows, behaving like the sub-auroral station $X$ plots with a minimum value of $\sim-22 \mathrm{nT}$.

\section{Ionospheric electrodynamics data}

Five ionosonde stations operating during the period of the case-study in a latitudinal range from the equator to mid-latitude appear useful to complement the identification of the convection electric field penetration to the equator. In fact, Bettencourt and Abdu (1981) have shown that for equatorial stations, the rate of change of the h' $F$ is indicative of the variations of F-region vertical plasma drift and thus of the zonal electric field when h'F is greater than about $300 \mathrm{~km}$, as is often the case in the evening pre-midnight period. Even for the lower altitudes of the h'F, however, rapid change of $h^{\prime} F$ generally indicates electric field perturbation. Oliver et al. (1991) and Yeh et al. (1994) pointed out that in general, lowlatitude auroral events are associated with severe ionospheric disturbances. The dynamic behaviour of the low-latitude and mid-latitude ionosphere can provide further evidence of the penetration of the convection electric field during low-latitude auroral events (Tanaka and Ohtaka 1996). It should be noted that for low-latitude, non-equatorial stations, the variations in h'F can also depend on meridional winds which raise or lower the height of the F layer (Chan and Walker, 1984; Tanaka, 1986). Therefore, in order to investigate zonal electric field perturbations of magnetospheric origin at these latitudes, meridional wind effects must be removed (Spiro et al., 1988). In this section, we will show the effect of the magnetospheric convection electric field from the electrodynamic behaviour of the disturbed structure of the ionosphere at equatorial and midlatitude ionosonde stations compared with that of quietday variations (24 May) previous to the magnetic storm of 27 May.

Locations of the observing stations used in this paper are listed in the Table 1. Figure 8 shows hourly variations of foF 2 on the left panel (a) and the corresponding h'F on the right panel (b). It should be noted that Korhogo is near the trough of the equatorial fountain, whereas Ouaga and Dakar seem to be located near the crest region. Noticable change consisting in a sudden increase and a rapid decrease can be observed in the h' $F$ behaviour during the pre-sunrise hours, namely in the time-interval 0400-0600 UT at Ouaga and 0500-0800 UT at Dakar. Due to gaps in the data at Korhogo we cannot directly point out similar change there. However, the two limits of the time-interval 0400-0600 UT suggest a possible occurrence of such a change. Subsequent to the change observed in h'F variations at the equator, the corresponding foF 2 variations undergo an increase that exceeded the reference quiet-time level about 0700 UT for Dakar and 0730 UT for Ouaga, whereas Korhogo experienced the same increase later at 1000 UT. The highest level reached can be observed at Dakar $(12.6 \mathrm{MHz})$ and Ouaga $(11.4 \mathrm{MHz})$ compared with Korhogo $(10.6 \mathrm{MHz})$, which is consistent with their respective position near the crest of the fountain for Dakar and Ouaga and in the trough for Korhogo as 

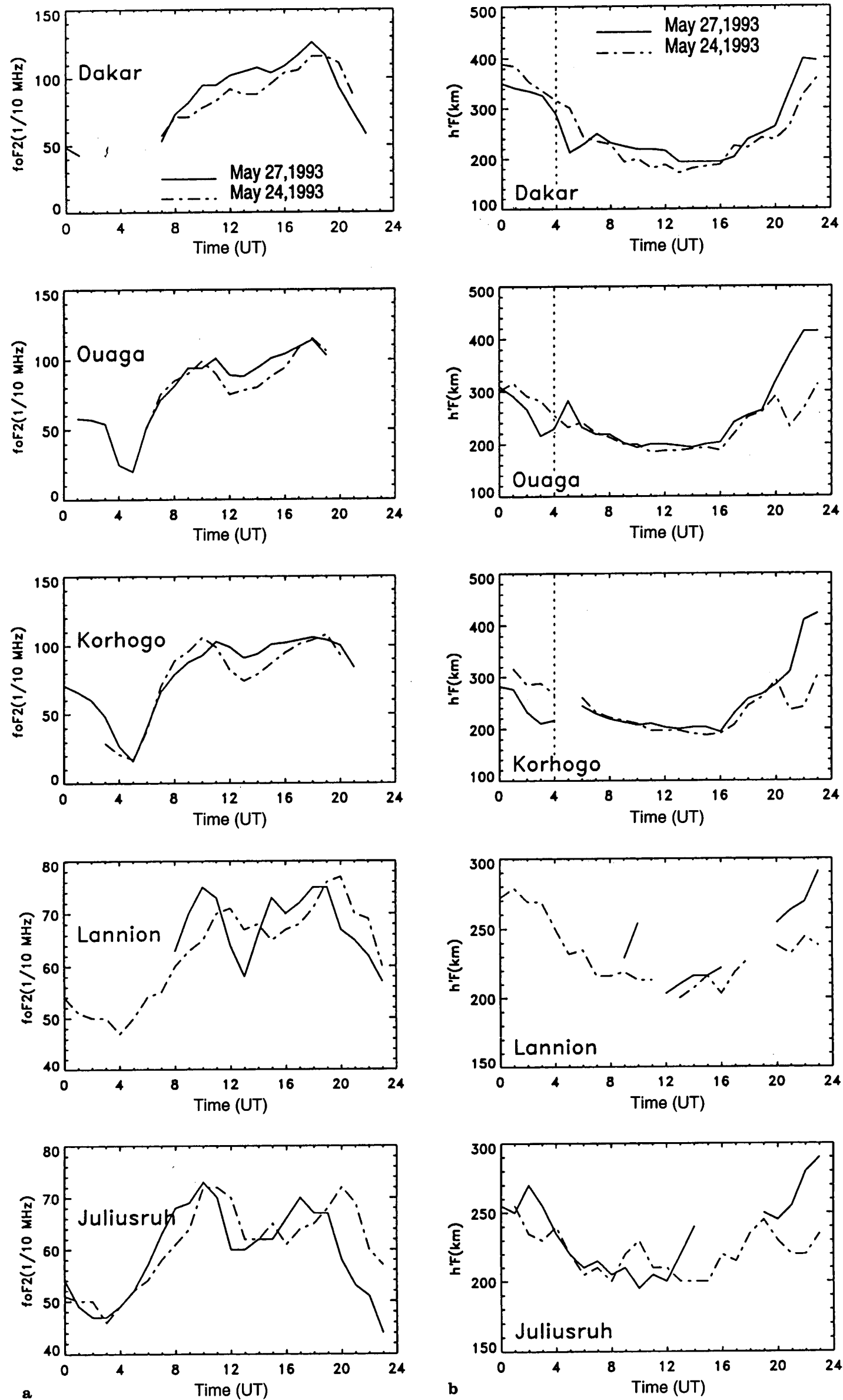
Fig. 8. a The foF 2 variations and b corresponding h'F variations from three ionosonde stations at the equator and middle latitude on 27 May 1993 (solid line) and on 24 May 1993, a quiet-day of the casestudy (dash-dotted line)

mentioned. It is worthy of note that after the foF 2 increase exceeded the quiet-day level, it remained higher until $1700 \mathrm{UT}$, revealing a super-fountain effect probably caused by the penetrating magnetospheric electric field during magnetospheric disturbance. Such an increase in h'F followed by the increase in foF 2 with a time-lag is a response of the low- and equatorial-latitude ionosphere to the penetration of the magnetospheric electric field (Tanaka, 1986; Tanaka and Ohtaka, 1996), the increase in the foF2 is delayed from h'F increases, because it takes some time to transport plasma from the equator to the crest region (Tanaka and Ohtaka, 1996). In general, the Equatorial Ionization Anomaly (EIA or the super-fountain effect) tends to be suppressed during disturbed periods (Tanaka, 1979), since disturbance dynamo electric fields cancel eastward electric field (Blanc and Richmond, 1980); but during geomagnetic storms, penetrating magnetospheric electric fields can cause these anomalous enhancements of the EIA (Tanaka and Ohtaka, 1996). The strikingly large uplift in the h'F layer of about 63, 94, $70 \mathrm{~km}$ at 2100 UT with respect to the quiet-day level at Dakar, Ouaga and Korhogo, respectively, is caused by the well-known pre-reversal enhancement of the vertical drift and corresponding post-sunset resurgence of the EIA (Woodman, 1970; Fejer et al., 1991; Abdu et al., 1981; Batista et al., 1986). These uplifts are concurrent with the decrease in the foF2, which means a drop in electron density simultaneously with an increase in the eastward component of the electric field; that is, an upward motion of the plasma near the magnetic equator due to the sudden increase in the eastward electric field, in agreement with Raghavarao and Sivaraman (1973). The same pattern is also observed in the European sector at 1900 UT (Lannion and Juliusruh). In addition, a noticeable decrease between 1100 and 1500 UT in foF2 seems to occur roughly in the same period of time with a change in the h'F layer, though due to gaps in the data it appears less evident. However, a remarkable uplift of about $120 \mathrm{~km}$ with respect to the quiet-time level in the h'F2 at Lannion (not shown) during the time-interval of 1100-1500 UT occured simultaneously with an antiphase change in foF2. This phenomenon appears temporally quite well correlated to the quasi-periodic oscillations well in phase at all latitudes in the $H$-component for the time-interval 1100-1300 UT.

A radar measurement at $4.2 \mathrm{MHz}$ performed on 27 May 1996 at Korhogo revealed irregular features. The radar used for these experiments is a high-resolution zenithal HF sounder. It is characterized by large possibilities of different experiment modes, mixing Doppler and echo measurement simultaneously at four selected sounding frequencies with ionograms and HF interferometry. The system transmits two pulses successively at two different frequencies in the range 1$30 \mathrm{MHz}$. The radar height resolution, determined by the pulse width $(10 \mu \mathrm{s})$ is $1.5 \mathrm{~km}$. The resolution time at the same radar frequency is $70 \mathrm{~ms}$. The precision of the height measurement is $750 \mathrm{~m}$. According to Blanc and Hounginou (1996), a large irregular layer is observed below the F1 region (not shown). It extends from 100 to $150 \mathrm{~km}$ at noon and appears just after $1000 \mathrm{UT}$. It is formed by scattering from irregularities in the electrojet region in the $100-150-\mathrm{km}$ range and in an intermediate region in the $150-160-\mathrm{km}$ range characterized by a downward motion in the morning and an upward motion in the evening similar to that of the F1 layer. Both regions are mixed at noon. The dimension of the irregularities observed in the present experiment is $33 \mathrm{~m}$ at the sounding frequency of $4.5 \mathrm{MHz}$, this scale is ten times larger than that of the irregularities observed at $50 \mathrm{MHz}$ at Jicamarca. The 3-m irregularities observed by the radar act just as a passive tracer of the largerscale kilometric motion. The dimension of the smallerscale irregularities is at least ten times larger in this experiment (compared to Jicamarca) as used frequency

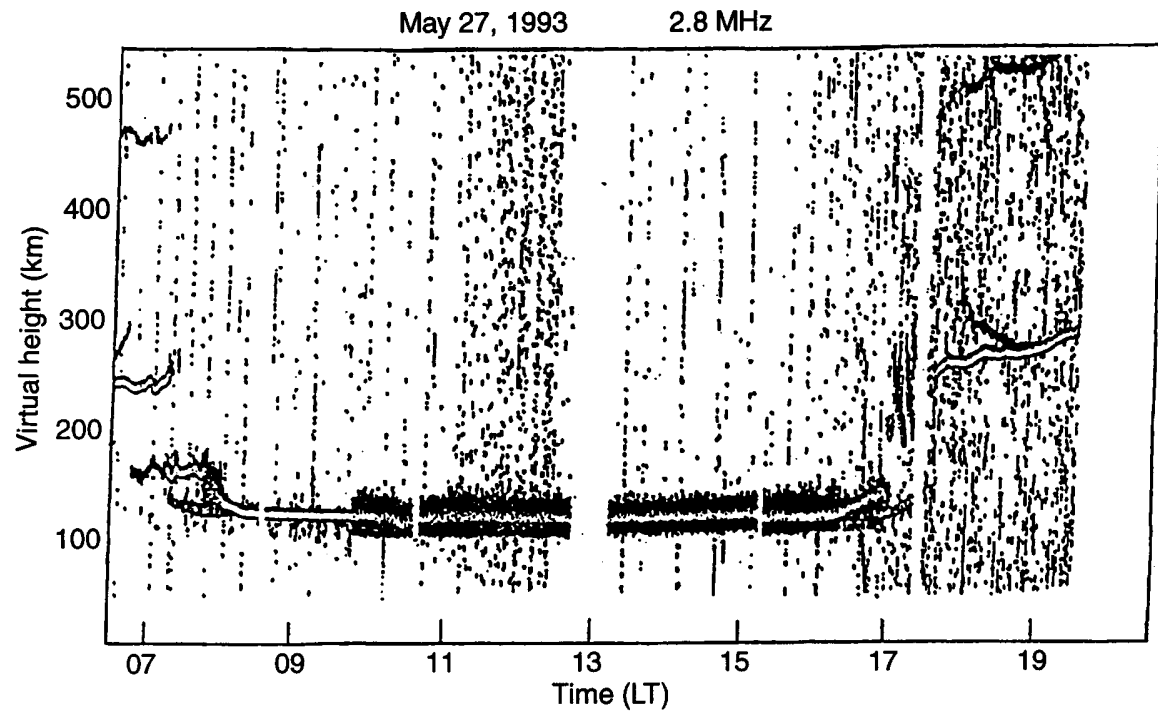

Fig. 9. HF radar plot at $2.8 \mathrm{MHz}$ of the equatorial electrojet irregularities on 27 May 1993 at Korhogo $\left(09.27^{\circ} \mathrm{N} ; 05.30^{\circ} \mathrm{W}\right)$. Irregularities are absent from 0800-0950 LT. NB: LT $=$ UT 
range 1-8 MHz corresponds to $150-18 \mathrm{~m}$. The strongest effects were observed at 3-5 MHz. Figure 9 shows an $\mathrm{HF}$ radar measurement at $2.8 \mathrm{MHz}$ of the EEJ irregularities for 27 May 1993 at KOR. Note the absence of irregularities during the time-interval of about 0800 0953 UT just after the end of the decrease in the Dst which started a recovery at 0730 UT. The irregularities' disapearance between 0800 and 0950 UT during the same period of decreasing $H$ and reversed $Z$ (Fig. 1b, d) indicates that a belt of current flows in the reverse direction with respect to the normal west-east electrojet flow (Fambitakoye et al., 1973). These E-region irregularities at equatorial latitude giving the appearance of $E s-q$ layer during daytime ionograms have been suggested to be due to cross-field instabilities (Rastogi, 1973b). The reversal of the electrojet currents indicated by the negative $H$ bay concurrently to the irregularities' disappearance between 0800 and 0950 UT are due to the temporary reversal of vertical Hall polarization field which corresponds to negative $V z$ (Rastogi and Rajaram, 1971; Rastogi, 1973a). This constitutes evidence of a westward electric field occurrence associated with polar substorm activity which superimposes on the normal eastward Sq electric field (Rastogi, 1973b, 1989). It may also be noted that before 0940 UT the width of the power spectra data at $-20 \mathrm{~dB}$ for the $\mathrm{E}$ region (not shown) is continuously around $0.29 \mathrm{~Hz}$ at $0904 \mathrm{UT}$, 0914 UT. However, this width increases to reach values of $1.19,2.08$ and $1.78 \mathrm{~Hz}$ at 0953,1003 and $1051 \mathrm{UT}$, respectively. These values remained above $0.29 \mathrm{~Hz}$ after 0953 UT, indicating the recovery and the strengthening of the eastward electric field from 0950 UT in the E region which tracks the sharp increase in the $H$ component at the equator from about 0830 UT. The occurrence of these irregularities subsequent to the disruption of the plasma drift pattern and the electron density distribution at equatorial latitude might suggest that the electric field of high-latitude origin penetration event may be responsible for the triggering of these large-scale 3-m irregularity generations recorded on 27 May 1993 after 0950 UT, in agreement with Fejer and Kelley (1980), Fejer et al. (1979a), and Fejer (1986).

\section{Observations, summaries and conclusions}

An equatorial electrojet response to a global-scale disturbance of 27 May 1993 by integrating observations from different longitude sectors at high, mid- and equatorial latitudes has been presented. The analysis revealed the different kinds of influence from the morning and afternoon cells. The first cell, incorporating the westward auroral and sub-auroral electrojet is closed partly by the eastward ionospheric return current flowing at mid- and equatorial latitudes. The second cell, exhibiting eastward auroral currents, is closed partly through the ring current and partly by ionospheric westward return currents flowing at sub-auroral, mid and equatorial latitudes. The quasi-periodic perturbations observed between 1100-1300 UT within the latter cell produce in-phase variations in magnetic field at all latitudes. There is however no one-to-one amplitude relation between the stations of the three regions: auroral, mid and equatorial latitude. But the near temporally correlated change in the $\mathrm{F}$ layer in the European sector between 1100 and 1500 UT confirms the signature of this event which is likely to be produced by the $D P 2$ currents or to some extent by the meridional wind. However, the return current of the afternoon auroral current circuit causes a reduction in the field strength at the equator. In fact, the ratio of about six of these fluctuations' magnitudes revealed the field attenuation at the equator in agreement with Reddy (1981). In order to cancel out the ring current and the $S_{R}$ origin variations we computed for the stations of the African network and specially at NIE the difference $H-D s t \cdot \cos L-S_{R}$, where $L$ is the geomagnetic dipole latitude of the station. The variations of this difference are the result of auroral origin activity (Fig. 10a, b). It appears quite different compared to Fig. 4a of 27 May 1993 which rather results from the following sum: $D s t+D P+S R$. It should be noted that the calculated variations are similar to those of the $X$-component of the auroral northernmost Scandinavian stations or LVG station. in addition, the suppression of the eastward electric field attested by the disappearance of irregularities between 0800 and 0950 UT simultaneously to the
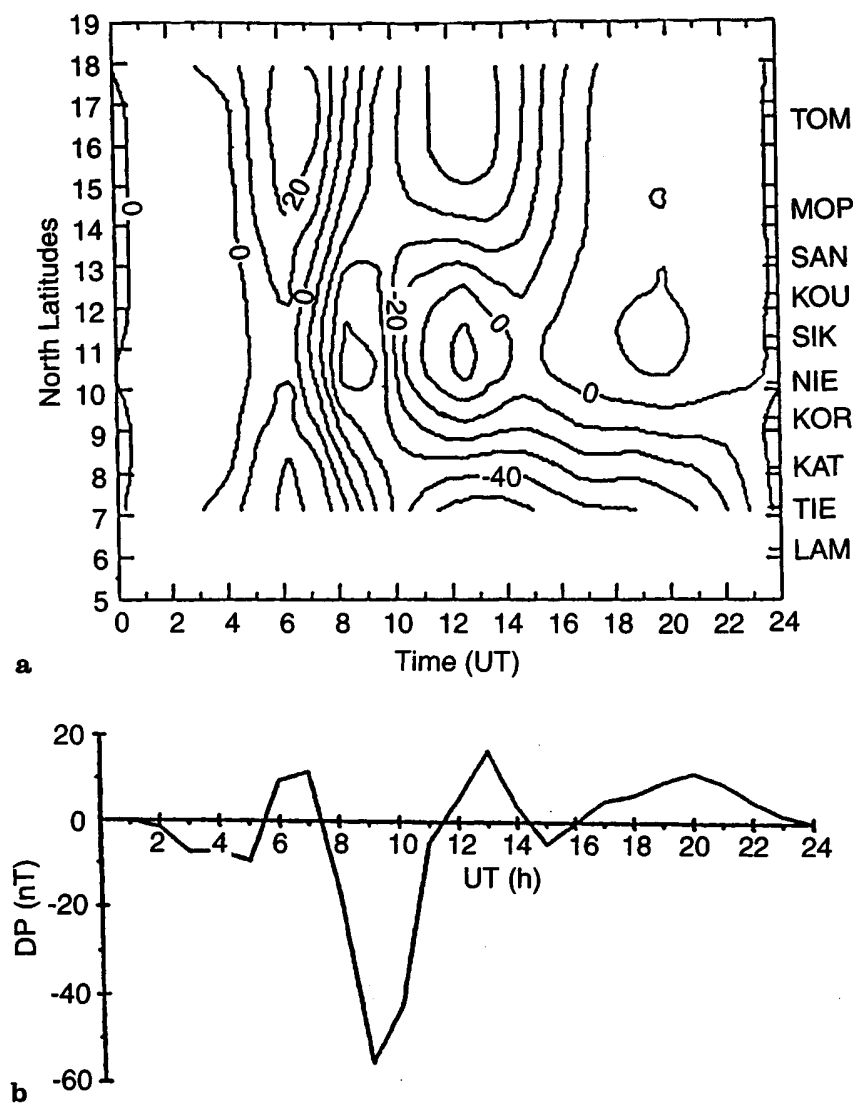

Fig. 10. a Isofield contours of $D P$ equivalent currents variations inferred from $H$ variations at the equator for the ten magnetic stations of the African network and b $D P$ variations inferred from $H$ variations at NIE 
decrease in $H$-component at the equator, mid- and subauroral latitude suggest that the equatorial ionosphere does not undergo the effect of the ring current but is rather affected by ionospheric current of high-latitude origin. This is evidenced by the large anti-phase to $H$-component increase of $D$-component (mostly between 0600 and 0830 UT) as a result of the current flow across the magnetic equator, either in the dynamo region or along the magnetic field lines (Schieldge et al., 1973) as well as the $D P$ contours (Fig. 10a) and the $D P$ plot at NIE (Fig.10b) of 27 May exhibiting a counter-electrojet signature. The super-fountain effect subsequent to the change in h'F during the pre-sunrise hours and the strong irregularities resurgence after 0950 UT constitute a corroborative evidence of high-latitude convection electric field penetration at the equator. Although models of coupled magnetosphere-ionosphere electric fields penetrating to low and equatorial latitudes predict that the electric fields penetrating to low latitudes should be damped on time-scale of the order of a few tens of minutes by the establishment of a shielding layer at the inner edge of the magnetospheric ring current, the observations indicate longer-lasting effects (Richmond, 1995). Finally, the observed magnetic variations recorded at NIE near the EEJ maximum on 27 May 1993 can be expressed as follows :

$\Delta H=S_{R}+D R+D P+D C F+D T$,

where the $D R, D C F$ and $D P$ components are caused by solar wind and magnetosphere interactions, whereas the $S_{R}$ is due to solar radiation and circulation in the atmosphere.

Acknowledgements. The IEEY experiment in the African sector reported here has been carried out in the framework of a cooperation program supported from ORSTOM, CEA, CETP, CNET/France Telecom, French Ministry of cooperation, University of Abidjan and PAIGH. The authors are grateful to A. D. Richmond for valuable remarks and to LIM-Institut für Meteorologie of Leipzig for providing Central Europe ionosonde data.

Topical Editor D. Alcaydé thanks R. G. Rastogi for help in evaluating this paper.

\section{References}

Abdu, M. A., J. A. Bittencourt, and I. S. Batista, Magnetic declination control of the equatorial $\mathrm{F}$ region dynamo electric field development and spread- F, J. Geophys. Res., 86, 1144311446, 1981.

Abdu, M. A., B. M. Reddy, G. O. Walker, R. Hanbaba, J. H. A. Sobral, B. J. Fejer, R. F. Woodman, R. W. Schunk, E. P. Szuszczewicz, Processes in the quiet and disturbed equatorial low-latitude ionosphere: SUNDIAL campaign 1984, Ann. Geophysicae, 6, 69-80, 1988.

Akasofu, S.-I., A source of energy for geomagnetic storms and auroras, Planet Space Sci., 12, 81-833, 1964.

Akasofu, S.-I., Magnetospheric substorm: a model in solar terrestrial physics, 1970: part II, D. Reider, Norwell, Mass., 1972.

Akasofu, S.-I., and S. Chapman, A neutral line discharge theory of auroras polaris, Phil. Trans. R. Soc. A 253, 359-406, 1961.
Akasofu, S.-I., and S. Chapman, The enhancement of the equatorial electrojet during polar magnetic substorms, J. Geophys. Res., 68, 2375-2382, 1963.

Batista, I. S., M. A. Abdu, and J. A. Bittencourt, Equatorial F region vertical plasma drift: seasonal and longitudinal asymmetries in the American sector, J. Geophys. Res., 91, 1205512064, 1986.

Bettencourt, J. A., and M. A. Abdu, A theoretical comparison between apparent and real vertical ionization drift velocities in the equatorial F-region, J. Geophys. Res., 86, 2451-2454, 1981.

Blanc, E., and H. Houngninou, Kilometric irregularities in the $\mathrm{E}$ and $\mathrm{F}$ regions of the daytime equatorial ionosphere observed by a high-resolution HF radar, Geophys. Res. Lett., 23, 645-648, 1996.

Blanc, M., and A. D. Richmond, The ionospheric disturbance dynamo, J. Geophys. Res., 85, 1669-1686, 1980.

Chan, H. F., and G. O. Walker, Computer simulation of the ionospheric equatorial anomaly in east Asia for equinoctial, solar minimum conditions. Part II. Results and discussion of wind effects, J. Atmos. Terr. Phys., 46, 1113-1120, 1984.

Doumouya, V., Etude des effets magnétiques de l'électrojet équatorial. PhD thesis, Université Nationale de Côte d'Ivoire, 1995.

Fambitakoye, O., R. G. Rastogi, J. Tabbagh, and P. Vila, Counterelectrojet and Esq disappearance, J. Atmos. Terr. Phys., 35, 1119-1126, 1973.

Fambitakoye, O., M. Menvielle, and C. Mazaudier, Global disturbance of transcient magnetic field associated with thermospheric storm winds on March 23, 1979, J. Geophys. Res., 95, 15209-15218, 1990.

Fejer, B. G., Equatorial ionospheric electric fields associated with magnetospheric disturbances, in Solar wind-magnetosphere coupling, Eds. Y. Kamide and J. A. Slavin, Terra Scientific Publishing Co., Tokyo, Japan, pp. 519-545, 1986.

Fejer, B. G., and M. C. Kelley, Ionospheric irregularities, Rev. Geophys. Space Phys., 18, 401-454, 1980.

Fejer, B. G., D. T. Farley, R. F. Woodman, and C. Calderon, Dependence of equatorial F-region vertical drifts on season and solar cycle, J. Geophys. Res., 84, 5792-5796, 1979a.

Fejer, B. G., E. R. de Paula, S. A. Gonzales, and R. F. Woodman, Average vertical and zonal $F$ region plasma drifts over Jicamarca, J. Geophys. Res., 96, 13901-13906, 1991.

Mayaud, P. N., Analyse morphologique de la variabilité jour à jour de la variation journalière et régulière $S R$ du champ magnetique terrestre, II le systeme de courant C (régions polaires), Ann. Geophys. 21, 514-544, 1965.

Mazaudier, C., C. Senior, and E. Nielsen, Global convection electric field and current: comparisons between model's predictions and data from STARE, Saint-Santin, and magnetometers, J. Geophys. Res., 92, 5991-5999, 1987.

Oliver, W. L., S. Fukao, T. Takami, T. Tsuda, and S. Kato, Fourbeam measurements of ionospheric structure with the MU radar during the low-latitude auroral event of October 20-23, 1989, Geophys. Res. Lett., 18, 1975-1980, 1991.

Onwumechilli, A., and P. O. Ogbuehi, Fluctuations in the geomagnetic horizontal field, J. Atmos. Terr. Phys. 24, 173-190, 1962.

Onwumechilli, A., K. Kawasaki, and S.-I. Akasofu, Equatorial electrojet and polar magnetic variations, Planet. Space Sci., 21, $1-16,1973$.

Raghavarao, R., and M. R. Sivaraman, Enhancement of the equatorial anomaly in the topside ionosphere during magnetic storms, J. Atmos. Terr. Phys., 35, 2091-2095, 1973.

Rastogi, R. G., Equatorial sporadic E and the electric field, J. Atmos. Terr. Phys. 35, 367-371, 1973 a.

Rastogi, R. G., Es-q layer at Huancayo during the March 1970 geomagnetic storm, Planet. Space Sci., 21, 197-201, 1973 b.

Rastogi, R. G., The equatorial electrojet in magnetic and ionospheric effects, in Geomagnetism, Ed. J. Jacobs, Academic Press, New York, pp. 461-525, 1989. 
Rastogi, R. G., and G. Rajaram, Electrojet effects on the equatorial F-region during magnetically quiet and disturbed days, Indian J. Rad. Space. Phys., 9, 531-536, 1971.

Reddy, C. A., The equatorial electrojet: a review of the ionospheric and geomagnetic aspect, J. Atmos. Terr. Phys, 43, 557-571, 1981.

Reddy, C. A., The equatorial electrojet, Pageophysics, 131, 487507, 1989 .

Reddy, C. A., V. V. Somayajulu, and C. V. Devasia, Global-scale electrodynamic coupling of the auroral and equatorial dynamo regions, J. Atmos. Terr. Phys., 41, 189-201, 1979.

Richmond, A. D., Modeling equatorial ionospheric electric field, J. Atmos. Terr. Phys, 57, 1103-1115, 1995.

Schieldge, J. P., S. V. Venkateswaran and A. D. Richmond, The ionospheric dynamo and equatorial magnetic variations, J. Atmos. Terr. Phys., 35, 1045-1061, 1973.

Spiro, R. W., R. A. Wolf, and B. G. Fejer, Penetration of highlatitude electric field to low latitude during SUNDIAL 1984, Ann. Geophysicae, 6, 39-50, 1988.
Sugiura, M. and S. Chapman, The average morphology of geomagnetic storms with sudden commencement, Abhandl. Akad. Wiss. Göttingen, Math-Phys. Kl. Sonderh. 4, 53-61, 1960.

Tanaka, T., The worldwide distribution of positive ionospheric storms, J. Atmos. Terr. Phys., 41, 103-110, 1979.

Tanaka, T., Low-latitude ionospheric disturbances: results for March 22, 1979, and their general characteristics, Geophys. Res. Lett., 13, 1399-1402, 1986.

Tanaka, T., and K. Ohtaka, Ionospheric disturbances during lowlatitude auroral events and their association with magnetospheric processes, J. Geophys. Res., 101, 17151-17159, 1996.

Woodman, R. F., Vertical velocities and east-west electric fields at the magnetic equator, J. Geophys. Res., 75, 6249-6259, 1970.

Yeh, K. C., S. Y. Ma, K. H Lin, and R. O. Conkright, Global ionospheric effects of the October 1989 geomagnetic storm, J. Geophys. Res., 99, 6201-6218, 1994. 